Echteld, M.A., Passchier, J., Teunissen, S., Claessen, S., Wit, R. de, Rijt, C.C.D. van der. Multidimensional fatigue and its correlates in hospitalised advanced cancer patients. European Journal of Cancer: 2007, 43(6), 1030-1036

\begin{tabular}{l|l}
$\begin{array}{l}\text { Postprint } \\
\text { Version }\end{array}$ & 1.0 \\
Journal website & http://dx.doi.org/10.1016/j.ejca.2007.01.024 \\
\hline Pubmed link & $\underline{\text { http://www.ncbi.nlm.nih.gov/pubmed/17336052 }}$ \\
\hline DOI & $10.1016 /$ j.ejca.2007.01.024
\end{tabular}

This is a NIVEL certified Post Print, more info at http://www.nivel.eu

\title{
Multidimensional fatigue and its correlates in hospitalised advanced cancer patients
}

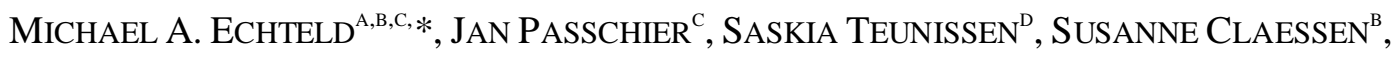 \\ RONALD DE WIT ${ }^{\mathrm{B}}$, Carin C.D. van der Rijt ${ }^{\mathrm{B}}$ \\ aVU University Medical Centre, Institute for Research in Extramural Medicine, Department of \\ Public and Occupational Health, \\ Amsterdam, The Netherlands \\ bErasmus MC-Daniel den Hoed Cancer Centre, Department of Medical Oncology, \\ Rotterdam, The Netherlands \\ cErasmus MC Department of Medical Psychology and Psychotherapy, Rotterdam, The \\ Netherlands \\ dUniversity Medical Centre Utrecht, Department of Medical Oncology, Utrecht, The \\ Netherlands
}

\begin{abstract}
A B S T R A C T
Although fatigue is a multidimensional concept, multidimensional fatigue is rarely investigated in hospitalised cancer patients. We determined the levels and correlates of multidimensional fatigue in 100 advanced cancer patients admitted for symptom control. Fatigue dimensions were general fatigue (GF), physical fatigue (PF), reduced activity (RA), reduced motivation (RM) and mental fatigue (MF). Investigated correlates were tumour load, prior anti-tumour treatment, medication use, haemoglobin levels, serum biochemical variables, physical symptoms and mood. Median GF, PF and RA scores were very high; median RM and MF scores were moderate, and differed from the GF, PF and RA scores. Multiple regression analyses showed that symptoms and mood correlated with all fatigue dimensions. Each fatigue dimension had different relationships with other factors. Hospitalised advanced cancer patients differ in fatigue levels depending on the fatigue dimension, and each fatigue dimension has different correlates. The results confirm that fatigue should be regarded as a multidimensional concept.
\end{abstract}

\section{INTRODUCTION}

Levels of five fatigue dimensions and a prospective analysis of correlates of fatigue in hospitalised advanced cancer patients are presented. Clinical research on fatigue in advanced cancer patients is important, because fatigue is an essential determinant of quality of life, health status and symptom burden. ${ }^{1-5}$ Fatigue is nominated by patients 
Echteld, M.A., Passchier, J., Teunissen, S., Claessen, S., Wit, R. de, Rijt, C.C.D. van der. Multidimensional fatigue and its correlates in hospitalised advanced cancer patients. European
Journal of Cancer: $2007,43(6), 1030-1036$

as the most important factor influencing daily functioning. ${ }^{6}$ Furthermore, fatigue is prevalent: fatigue in excess of the 95th percentile of a healthy control group was present in $78 \%$ of cancer patients receiving specialist inpatient palliative care. ${ }^{3}$ In a recent systematic review (46 studies, including 26,223 advanced cancer patients), the prevalence of fatigue was $64 \%$ in studies concerning the last 1-2 weeks of life and $75 \%$ in other studies. ${ }^{7}$ While there is little debate about the importance of fatigue as a determinant of illbeing, adequate methods of managing fatigue are lacking, also because the aetiology of fatigue in advanced cancer is unknown. This study aims to provide knowledge of potential determinants of fatigue, which may help physicians make informed treatment decisions.

The multidimensional conceptualisation of fatigue is widely accepted ${ }^{8-10}$; fatigue manifests itself in multiple, reasonably independent ${ }^{11}$ dimensions, e.g. physical, cognitive, motivational, or in terms of reduced activities. Nevertheless, fatigue is seldom investigated as a multidimensional construct in hospitalised advanced cancer patients. In palliative care research fatigue is labelled differently in different studies: tiredness, weakness and asthenia are used as synonyms. This complicates the generalisability of results even more in the often heterogenic palliative care populations. In a recent study, Munch and colleagues investigated correlates of multidimensional fatigue in advanced cancer. They found that anxiety and especially depression were related to fatigue dimensions, but the strength of the relationships varied fromdimension to dimension. The authors suggested that the different dimensions of fatigue in their study measure different aspects of fatigue.

${ }^{12}$ In an earlier study, Shun and colleagues also found relationships between anxiety and depression and fatigue. In other studies, more possible correlates of fatigue were identified.

Symptoms and symptom distress were identified as significant correlates in a number of studies examining advanced cancer patients receiving anti-tumour treatment.

${ }^{13-16}$ Jacobson and colleagues found that greater declines in haemoglobin levels were related to increases in fatigue duration and disruptiveness. ${ }^{17}$ Opioids and other centrally functioning medication, ${ }^{12}$ and (prior) anti-tumour therapy were also identified as a factor influencing fatigue. ${ }^{13,18}$ Lastly, a positive response of fatiguewas found on the administration of corticosteroids. ${ }^{19}$ Additional likely correlates of fatigue include stage of disease, tumour load, markers for liver and renal function, anti-emetics, anti-convulsants and weight loss.

In this prospective study, fatigue is conceptualised as a multidimensional construct. Differences in levels and distributions of fatigue dimensions were determined, and relationships between all the above-mentioned medical and psychological variables and the fatigue dimensions were explored.

The patients studied in this work were all admitted for symptom control. Therefore, it was hypothesised that they would exhibit high levels of physical fatigue and reduced activity. It was also hypothesised that due to the independence of the fatigue dimensions, each fatigue dimension will result in a different predictive model of correlates.

\section{PATIENTS AND METHODS}

\subsection{Patients}

One hundred patients with advanced cancer admitted to the palliative care unit (PCU) of the Erasmus MC Daniel den Hoed Cancer Centre were included. All 
Echteld, M.A., Passchier, J., Teunissen, S., Claessen, S., Wit, R. de, Rijt, C.C.D. van der. Multidimensional fatigue and its correlates in hospitalised advanced cancer patients. European
Journal of Cancer: $2007,43(6), 1030-1036$

patients were admitted for symptomcontrol. Of the 263 patientswhowere asked to participate in the study, 100 did not fulfil the inclusion criteria: 62 patients appeared to have received immuno- or chemotherapy within 4 weeks prior to PCU admission, 34 patients could not be interviewed due to cognitive impairment, 4 patients had life expectancies of less than 14 days, and 2 patients had insufficient command of the Dutch language. Two patients were cognitively impaired and had life expectancies of less than 14 days.

Of the remaining patients, 33 patients refused participation, and 30 patients could not be included due to other reasons.

\subsection{Data collection}

Data were collected within $48 \mathrm{~h}$ after admission by trained oncology nurses. Sociodemographic data and data on antitumour therapies and medication use were collected from the medical records. All other datawere obtained by interview using the instruments listed below. Ethical clearance was provided by the Medical Ethical Committee of the Erasmus Medical Centre.

\subsection{Measures}

The multidimensional fatigue inventory (MFI) ${ }^{11}$ was used for the measurement of multidimensional fatigue. The MFI consists of 20 statements of which patients are requested to indicate agreement on a five-point scale. The MFI measures five dimensions of fatigue: general fatigue $(\mathrm{GF})$, physical fatigue $(\mathrm{PF})$, reduced activity (RA), reduced motivation (RM) and mental fatigue (MF). Scores range from 4 to 20 (higher values indicate more fatigue). The Hospital Anxiety and Depression Scale ${ }^{20}$ (HADS), a 14-item questionnaire with four-point rating scales, was used to measure anxiety and depression. Scores range from 0 to 20 (higher scores denote more distress); patients with 'probable' anxiety and/or depressive disorder are identified with scores P11. Physical symptoms were measured with the symptom subscale of the European Organization for Research and Treatment of Cancer QLQ C-30. ${ }^{21}$ Patients indicate on four-point rating scales to what extent they suffer from dyspnoea, pain, need for rest, sleeping difficulties, weakness, lack of appetite, nausea, vomiting, diarrhoea and fatigue (range 1-4; higher values indicate higher symptom levels). Data on itch and hiccups were additionally collected using visual analogue scales. Symptom load was calculated by counting the number of these 12 physical symptoms present in each patient (symptom intensity $>0$; see Table 1 ). The fatigue-related items from the EORTC QLQ C-30 (need for rest, weakness and fatigue) were not used in the analyses on correlates of fatigue, because they measure the same construct as the outcome variable. Functional status was measured with the Palliative Performance Scale (PPS ${ }^{22}$ ) with which staff members assigned a performance percentage score (higher percentages indicate better performance). Tumour load was defined as the number of organs involved and serum LDH level. Prior anti-tumour treatment variables were the number of chemotherapy lines, one or more instances of prior chemotherapy, one or more instances of prior radiotherapy, and one or more instances of prior immunotherapy.

Haemoglobin levels and serum biochemical variables were obtained through blood samples. All medication was coded given (1) or not (0), except opiates, for which the daily dose used was expressed as dose in oral morphine equivalents before coding it into three range categories: no morphine, below the median dose value and above the median dose value. 
Echteld, M.A., Passchier, J., Teunissen, S., Claessen, S., Wit, R. de, Rijt, C.C.D. van der. Multidimensional fatigue and its correlates in hospitalised advanced cancer patients. European Journal of Cancer: 2007, 43(6), 1030-1036

\subsection{Statistical methods}

Differences between fatigue dimensions were tested with Friedman's v2 test. Initial bivariate relationships were tested with Pearson correlations, Oneway analyses of variance and Student's t-tests. When the p-values of these relationships with the fatigue dimensions were 60.10, the correlates were entered into multiple linear regression analyses. Regression analyses estimate coefficients of equations that best predict the value of the outcome variables using multiple independent variables, and which shows the unique contributions of the independent variables to the outcome variables' variance.

The 'backward elimination' method for entering correlates into the regression equation was used. Correlates with a probability of FP0.10 were removed from the regression equation. P-values of 6.05 were considered significant. Analyses were performed using SPSS for Windows version 13.0.

\section{[TABLE 1] [TABLE 2]}

\section{RESULTS}

\subsection{Patient inclusion}

Patient characteristics, survival and prior anti-tumour treatment are presented in Table 1. The median number of symptoms was high, more than half of the patients had considerable functional limitations, and a third respectively a quarter of the patients showed signs of clinical depression respectively anxiety. Median survival after admission was 63 days.

\subsection{Distributions and correlates of fatigue dimensions}

Distributions of GF, PF and RA were skewed, showing Skewness values of _1.28, _1.28, and _1.48, respectively. Skewness values of RM and MF were between 0 and _ 1. Intercorrelations between the fatigue dimensions and internal consistency measures are shown in Table 2. Median scores of GF, PF and RA were very high (Fig. 1); scores 19-20 were found in 43\%, 59\%, and 48\% of the patients, respectively. Median scores for RM and MF were moderate and differed significantly from the GF, PF and RA scores (Friedman v2 $=157.3 ; \mathrm{p}<.01$ ). RM and MF scores varied widely between the lowest and the highest possible score (420).

Bivariate correlations between the targeted correlates and the fatigue dimensions are shown in Table 3. Only loss of appetite and depression were significantly related with all fatigue dimensions. Nausea was significantly related to all fatigue dimensions, although the relationship between nausea and physical fatigue was a trend $(.05<\mathrm{p} 6$.10). Other important correlates in terms of the number of fatigue dimensions with significant relationships were anxiety, dyspnoea and the levels of haemoglobin and albumin.

\section{[FIGURE 1]}

Results of the multiple regression analyses are shown in Table 4. The percentages explained variance differed from moderate to fair. The regression models were different for each fatigue dimension. Depression was a correlate of GF, RA and RM. Dyspnoea was a correlate in GF and PF, and nausea in PF and RA. ALAT and haemoglobin levels, opioid and anti-convulsant use, and previous immunotherapy 
Echteld, M.A., Passchier, J., Teunissen, S., Claessen, S., Wit, R. de, Rijt, C.C.D. van der. Multidimensional fatigue and its correlates in hospitalised advanced cancer patients. European Journal of Cancer: 2007, 43(6), 1030-1036

were other correlates of one of the fatigue dimensions. Correlates of MF, anxiety and pain, were not present in any other model.

In addition, a number of correlates were uniquely related to one fatigue dimension (lack of appetite, anxiety, pain, levels of haemoglobin levels and, ALAT, anticonvulsant use, and previous immunotherapy). PF was the only dimension without psychological correlates. A number of correlates that were identified in the bivariate analyses were excluded from the multiple regression equations. Additional correlation analyses showed that multicollinearity may have determined the incongruence between bivariate and multivariate analyses.

Symptoms of the digestive tract (loss of appetite, nausea and vomiting) appeared to be strongly interrelated $(\mathrm{r}=.46-0.79)$, and also related to use of anti-emetics $(\mathrm{r}=$ .25-0.41).

\section{DISCUSSION}

The patients in this study experienced severe fatigue as measured by the levels of GF, PF and RA; RM and MF levels were lower. Symptoms were related to all fatigue dimensions; especially depression, dyspnoea and nausea had strong correlations with many fatigue dimensions. The bivariate correlations showed that many factors were correlated with fatigue, but were not independently related to fatigue, as shown by the multiple regression analyses. As hypothesised, fatigue distributions and correlates were different for each fatigue dimension, which suggest that multidimensional conceptualisation of fatigue is justified. An important observation is that GF does not seem to be a 'sum' of all fatigue dimensions - it had correlates (opioid use and haemoglobin level) that did not relate to other dimensions. It is also notable that percentages explained variances were no greater than moderate to fair (19-45\%): in this study, fatigue seems to present itself as a quality partly independent from symptom and treatment characteristics. However, several tumour-related variables, e.g. cytokines, were not measured.

The results are in agreement with the study of Munch and colleagues, ${ }^{12}$ who also used the MFI and the HADS. They found that depression and anxiety were correlates of fatigue.

As in the current study, using bivariate correlations, Munch and colleagues found that depression was related to all fatigue dimensions. Anxiety was not related to all dimensions, but to GF en MF only; in the current study, an additional relationship with RM was found. Furthermore, internal consistency measures were found to be adequate, as was found in the Munch and colleagues and current study. The current study explained more variance than in the Munch et al study, and showed that more variables are valid correlates than depression and anxiety alone. These differences can be explained by the analyses (bivariate correlations in Munch and colleagues versus multiple regression analyses in the current study) and the larger number of possible correlates in the current study.

The results are congruent with other studies that identified psychological distress, pain, dyspnoea and haemoglobin level as correlates of fatigue. ${ }^{3,17,23,24}$ From another point of view, Smith and colleagues found significant associations between depression and fatigue, and between anxiety and fatigue and nausea after correction for pain and illness severity as a result of a multiple regression analysis in an advanced cancer population. ${ }^{25}$ The contrary is found in a sample of palliative care patients admitted for symptom control: high levels of anxiety and depression but no 
Echteld, M.A., Passchier, J., Teunissen, S., Claessen, S., Wit, R. de, Rijt, C.C.D. van der. Multidimensional fatigue and its correlates in hospitalised advanced cancer patients. European
Journal of Cancer: $2007,43(6), 1030-1036$

relationship with the presence nor with the intensity of fatigue or other physical symptoms. ${ }^{7}$ In another study, ${ }^{26}$ a verbal rating scale for mood was correlated with verbal rating scores for pain and fatigue and no significant differences in fatigue rating between depressed and non-depressed patients were found.

This study shows that psychological distress, pain, dyspnoea and haemoglobin level relate to different dimensions of fatigue. In addition, symptoms not often identified as correlates of fatigue in the literature may be important, such as lack of appetite, nausea and vomiting. It is notable that sleeping difficulties are not correlated with any of the fatigue dimensions. Other not often identified correlates are ALAT levels and the treatment modalities anti-convulsant use, opioid use, and previous immunotherapy. All treatment modalities had negative relationships with fatigue, which means that the treatments were associated with less fatigue. With regard to ALAT and immuno therapy, the reverse relationships were expected. The relationships between opioid and anti-convulsant use and fatigue dimensions may bemediated by pain levels - their use in this population may be associated with better pain control, which in turn may lead to less fatigue.

Only seven patients received previous immunotherapy, which means that the relationship should be interpreted with caution, and corroborated in larger-scale studies in more varied patient groups.

\section{[TABLE 3]}

Generalisation of the results to other advanced cancer populations may not be justified, because patients admitted to the PCU, by definition, have high symptom loads. Not only the fatigue dimensions GF, PF and RA were skewed, but also many of the correlates, which indicate that other correlates may be present in different populations. Furthermore, this study does not allow for causal statements to be made - causal relationships can only be explored in longitudinal studies.

Suggestions for future research include longitudinal studies in different advanced cancer populations in order to (a) investigate whether different correlates of multidimensional fatigue are present in different populations, and (b) to explore causal relationships between predictors and fatigue dimensions.

Intervention studies on better symptom control with fatigue as outcome should also give clues about causality.

Lastly, particularly relevant for palliative care research would be to investigate whether the different fatigue dimensions predict quality of life differently.

The aim of this study was to provide knowledge of potential determinants of fatigue in order to help clinicians to make informed treatment decisions. Treatment may target factors that are known to be related to affected fatigue dimensions in patients. In addition, the results give doctors and nurses the opportunity to come to a more indepth discussion with their patients and co-workers regarding patients' fatigue. In conclusion, most patients experienced extreme physical fatigue, but motivation and mental functioning seemed to be less impaired. This suggests that these patients are relatively capable and willing to perform mentally taxing tasks, but unable to carry out physically demanding roles. The results thus confirm the multidimensional nature of fatigue and clearly show the advantages ofmultidimensional fatigue conceptualisation: patientsmay differ in fatigue levels depending on the fatigue dimension, and each fatigue dimension has different correlates. These findings are a 
Echteld, M.A., Passchier, J., Teunissen, S., Claessen, S., Wit, R. de, Rijt, C.C.D. van der. Multidimensional fatigue and its correlates in hospitalised advanced cancer patients. European Journal of Cancer: 2007, 43(6), 1030-1036

new and an important step in the process of better understanding fatigue in advanced cancer.

\section{[TABLE 4]}

Conflict of interest statement None declared.

Acknowledgement This study is supported by Erasmus MC, Rotterdam, The

Netherlands.

\section{REFERENCES}

1. Aranda S, Schofield P,Weih L, et al. Mapping the quality of life and unmet needs of urban women with metastatic breast cancer. Eur J Cancer Care 2005;14:211-22.

2. Fang FM, Liu YT, Tang Y, Wang CJ, Ko SF. Quality of life as a survival predictor for patients with advanced head and neck carcinoma treated with radiotherapy. Cancer 2004;100:425-32.

3. Stone P, Richards M, A'Hern R, Hardy J. A study to investigate the prevalence, severity and correlates of fatigue among patients with cancer in comparison with a control group of volunteers without cancer. Ann Oncol 2000;11:561-7.

4. Brown DJ, McMillan DC, Milroy R. The correlation between fatigue, physical function, the systemic inflammatory response, and psychological distress in patients with advanced lung cancer. Cancer 2005;103:377-82.

5. Houck K, Avis NE, Gallant JM, Fuller Jr AF, Goodman A. Quality of life in advanced ovarian cancer: identifying specific concerns. J Palliat Med 1999;2:397-402.

6. Curt GA, Breitbart W, Cella D, et al. Impact of cancer-related fatigue on the lives of patients: new findings from the Fatigue Coalition. Oncologist 2000;5:353-60.

7. Teunissen SCCM, Wesker W, Kruitwegen C, De Haes JCJM, Voest EE, De Graeff A. Symptom prevalence in patients with incurable cancer: a systematic review. J Pain Symptom Manage 2007; in press.

8. Sood A, Moynihan TJ. Cancer-related fatigue: an update. Curr Oncol Rep 2005;7:277-82.

9. de Jong N, Candel MJ, Schouten HC, Abu-Saad HH, Courtens AM. Course of mental fatigue and motivation in breast cancer patients receiving adjuvant chemotherapy. Ann Oncol 2005;16:372-82.

10. Richardson A. Measuring fatigue in patients with cancer.

Support Care Cancer 1998;6:94-100.

11. Smets EMA, Garssen B, Bonke B, De Haes JCJM. The multidimensional fatigue inventory (MFI) psychometric qualities of an instrument to assess fatigue. J Psychosomat Res 1995;39:315.

12. Munch TN, Stromgren AS, Pedersen L, Petersen MA, Hoermann L, Groenvold M. Multidimensional measurement of fatigue in advanced cancer patients in palliative care: an application of the multidimensional fatigue inventory. J Pain Symptom Manage 2006;31:533-41.

13. Shun S-C, Lai Y-H, Jing T-T, et al. Fatigue patterns and correlates in male liver cancer patients receiving transcatheter hepatic arterial chemoembolization. Support Care Cancer 2005;13:311-7.

14. Berger AM, Higginbotham P. Correlates of fatigue during and following adjuvant breast cancer chemotherapy: a pilot study.

Oncol Nurs Forum 2000;27:1443-8.

15. Okuyama T, Tanaka K, Akechi T, et al. Fatigue in ambulatory patients with advanced lung cancer: prevalence, correlated factors, and screening. J Pain Symptom Manage $2001 ; 22: 554-64$.

16. Irvine D, Vincent L, Graydon JE, Bubela N, Thompson L. The prevalence and correlates of fatigue in patients receiving treatment with chemotherapy and radiotherapy. A comparison with the fatigue experienced by healthy individuals. Cancer Nurs 1994;17:36778.

17. Jacobsen PB, Garland LL, Booth-Jones M, et al. Relationship of hemoglobin levels to fatigue and cognitive functioning among cancer patients receiving chemotherapy. J Pain Symptom Manage 2004;28:7-18. 
Echteld, M.A., Passchier, J., Teunissen, S., Claessen, S., Wit, R. de, Rijt, C.C.D. van der. Multidimensional fatigue and its correlates in hospitalised advanced cancer patients. European Journal of Cancer: 2007, 43(6), 1030-1036

18. Richardson A, Ream E, Wilson-Barnett J. Fatigue in patients receiving chemotherapy: patterns of change. Cancer Nurs 1998;21:17-30.

19. Lundstrom SH, Furst CJ. The use of corticosteroids in Swedish palliative care. Acta Oncol 2006;45:430-7.

20. Zigmond AS, Snaith RP. The Hospital Anxiety and Depression Scale. Acta Psychiatr Scand 1983;67:361-70.

21. Aaronson NK, Ahmedzai S, Bergman B, et al. The European Organization for Research and Treatment of Cancer QLQ-C30: a quality-of-life instrument for use in international clinical trials in oncology. J Natl Cancer Inst 1993;85:365-76.

22. Anderson F, Downing GM, Hill J, Casorso L, Lerch N. Palliative performance scale (PPS): a new tool. J Palliat Care 1996;12:5-11.

23. Hwang SS, Chang VT, Rue M, Kasimis B. Multidimensional independent predictors of cancer-related fatigue. J Pain Symptom Manage 2003;26:604-14.

24. Stone P, Hardy J, Broadley K, Tookman AJ, Kurowska A, A'Hern R. Fatigue in advanced cancer: a prospective controlled crosssectional study. Br J Cancer 1999;79:1479-86.

25. Smith EM, Gomm SA, Dickens CM. Assessing the independent contribution to quality of life from anxiety and depression in patients with advanced cancer. Palliat Med 2003;17:509-13.

26. Lloyd-Williams M, Dennis M, Taylor F. A prospective study to determine the association between physical symptoms and depression in patients with advanced cancer. Palliat Med 2004;18:558-63. 
Echteld, M.A., Passchier, J., Teunissen, S., Claessen, S., Wit, R. de, Rijt, C.C.D. van der. Multidimensional fatigue and its correlates in hospitalised advanced cancer patients. European Journal of Cancer: 2007, 43(6), 1030-1036

\section{TABLES AND FIGURE}

Table 1 - Patient characteristics, survival, prior antitumour treatment, and distributions of diagnoses, metastases, symptom count and functional status scores $(\mathbf{N}=100)$

\begin{tabular}{|c|c|c|}
\hline & $\mathrm{N}$ & Median (range) \\
\hline Age & & $57.5(29-78)$ \\
\hline \multicolumn{3}{|l|}{ Gender } \\
\hline Men & 46 & \\
\hline Women & 54 & \\
\hline Survival (days) & & $63.0(5-911)$ \\
\hline \multicolumn{3}{|l|}{ Treatment before inclusion } \\
\hline Chemotherapy & 64 & \\
\hline Radiotherapy & 72 & \\
\hline Immunotherapy & 7 & \\
\hline \multicolumn{3}{|l|}{ Primary cancer site } \\
\hline Breast & 25 & \\
\hline Gastrointestinal & 17 & \\
\hline Lung and mesothelioma & 12 & \\
\hline Urogenital & 12 & \\
\hline Head and neck & 5 & \\
\hline Other & 22 & \\
\hline \multicolumn{3}{|l|}{ Tumour localisations } \\
\hline Bone & 46 & \\
\hline Lymph nodes & 43 & \\
\hline Lung & 40 & \\
\hline Liver & 25 & \\
\hline Pleura & 15 & \\
\hline Intra-abdominal & 8 & \\
\hline Brain & 7 & \\
\hline Skin & 7 & \\
\hline Other & 15 & \\
\hline Total number of organs involved & & $2.0(1-8)$ \\
\hline \multicolumn{3}{|l|}{ Symptoms and functional status } \\
\hline Symptom count with intensity $>0^{2}$ & & $8.0(2-12)$ \\
\hline $\begin{array}{l}\text { Functional status } \\
\text { (Palliative Performance Scale) }\end{array}$ & & $60.0(30-90)$ \\
\hline Depression scores $\geqslant 11$ & 33 & \\
\hline Anxiety scores $\geqslant 11$ & 26 & \\
\hline
\end{tabular}


Echteld, M.A., Passchier, J., Teunissen, S., Claessen, S., Wit, R. de, Rijt, C.C.D. van der. Multidimensional fatigue and its correlates in hospitalised advanced cancer patients. European Journal of Cancer: 2007, 43(6), 1030-1036

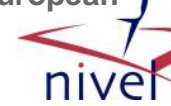

Table 2 - Pearson correlations between fatigue dimensions and internal consistencies (Crohnbach's Alpha) of each dimension

\begin{tabular}{|c|c|c|c|c|c|}
\hline & \multicolumn{5}{|c|}{ Fatigue dimensions } \\
\hline & $\begin{array}{l}\text { General fatigue } \\
\text { (GF) }\end{array}$ & $\begin{array}{l}\text { Physical fatigue } \\
\text { (PF) }\end{array}$ & $\begin{array}{l}\text { Reduced activity } \\
\text { (RA) }\end{array}$ & $\begin{array}{l}\text { Reduced motivation } \\
\text { (RM) }\end{array}$ & $\begin{array}{l}\text { Mental fatigue } \\
\text { (MF) }\end{array}$ \\
\hline General fatigue & - & & & & \\
\hline Physical fatigue & $.53^{\circ}$ & - & & & \\
\hline Reduced activity & $.21^{\circ}$ & $.50^{\circ}$ & - & & \\
\hline Reduced motivation & $.40^{\circ}$ & $.42^{\circ}$ & $.53^{\circ}$ & - & \\
\hline Mental fatigue & .12 & .15 & $.24^{\circ}$ & $.39^{*}$ & - \\
\hline Crohnbach's alpha & .75 & .68 & .75 & .78 & .84 \\
\hline
\end{tabular}

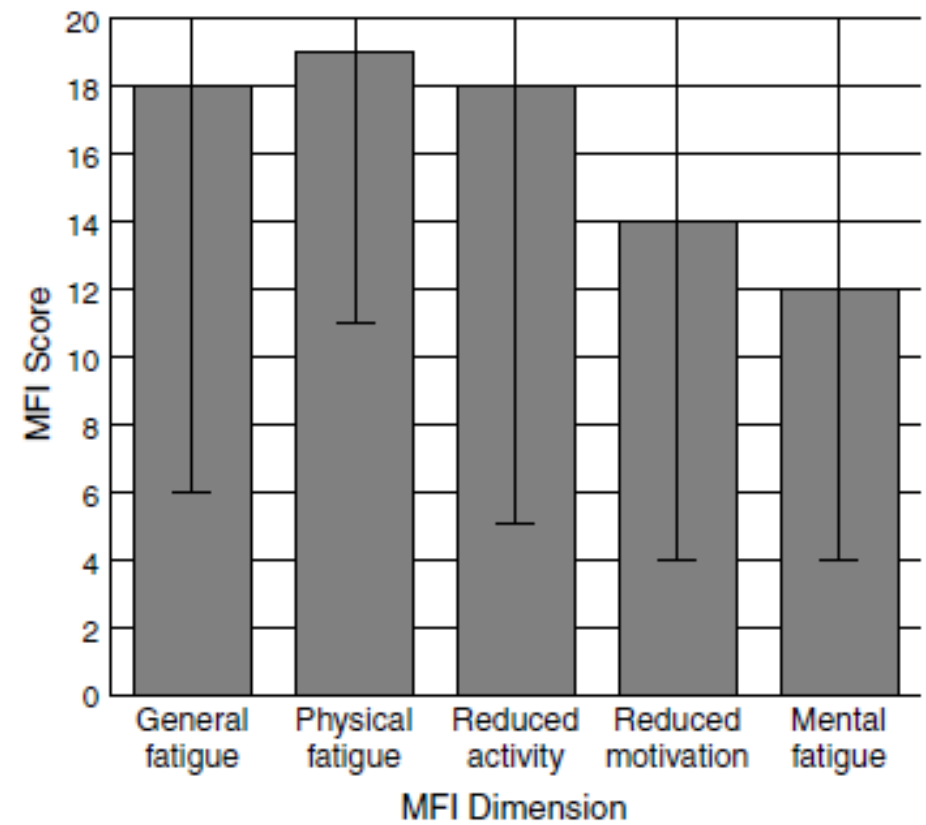

Fig. 1 - Median scores of each of the five MrI fatigue dimensions. The error bars represent minimum and maximum fatigue scores. 
Echteld, M.A., Passchier, J., Teunissen, S., Claessen, S., Wit, R. de, Rijt, C.C.D. van der. Multidimensional fatigue and its correlates in hospitalised advanced cancer patients. European Journal of Cancer: 2007, 43(6), 1030-1036

Table 3 - Pearson correlations between all correlates and the five fatigue dimensions

\begin{tabular}{|c|c|c|c|c|c|}
\hline & \multicolumn{5}{|c|}{ Fatigue dimensions } \\
\hline & $\begin{array}{l}\text { General fatigue } \\
\text { (GF) }\end{array}$ & $\begin{array}{l}\text { Physical fatigue } \\
\text { (PF) }\end{array}$ & $\begin{array}{l}\text { Reduced activity } \\
\text { (RA) }\end{array}$ & $\begin{array}{l}\text { Reduced motivation } \\
\text { (RM) }\end{array}$ & $\begin{array}{l}\text { Mental fatigue } \\
\text { (MF) }\end{array}$ \\
\hline Age & .116 & .059 & .096 & .148 & -.084 \\
\hline Dyspnea & $.246^{\circ}$ & $.238^{\circ}$ & -.004 & .041 & $-.206^{*}$ \\
\hline Pain & -.070 & -.024 & -.032 & -.007 & $.316^{* *}$ \\
\hline Difficulty in sleeping & .114 & .074 & .099 & .001 & .096 \\
\hline Loss of appetite & $.327^{*}$ & $.240^{\circ}$ & $.195^{\circ}$ & $.376^{*}$ & $.206^{\circ}$ \\
\hline Nausea & $.259^{*}$ & $.183^{-\cdots}$ & $.286^{*}$ & $.319^{*}$ & $.214^{\circ}$ \\
\hline Vomiting & $.239^{\circ}$ & .107 & .101 & $.270^{*}$ & $.188^{*-}$ \\
\hline Diarrhoea & $.316^{*}$ & $.169^{-*}$ & $.181^{*}$ & $.208^{\circ}$ & -.011 \\
\hline Itch & $-.183^{*}$ & -.097 & -.151 & -.112 & -.076 \\
\hline Hiccups & $.237^{\circ}$ & $.185^{* *}$ & .126 & .109 & -.035 \\
\hline Anxiety & $.254^{\circ}$ & .149 & .084 & $.321^{*}$ & $.357^{*}$ \\
\hline Depression & $.435^{*}$ & $.27^{*}$ & $.383^{\prime \prime}$ & $.619^{*}$ & $.274^{*}$ \\
\hline Opioids ${ }^{2}$ & $-.262^{*}$ & -.131 & -.113 & $-.167^{+*}$ & .099 \\
\hline Anti-convulsants ${ }^{b}$ & -.132 & $-.168^{* *}$ & -.079 & -.124 & .086 \\
\hline Anti-emetics ${ }^{\mathrm{b}}$ & $.199^{\circ}$ & .037 & .078 & .124 & .036 \\
\hline Benzodiazepines $^{b}$ & -.030 & .032 & -.033 & -.082 & .014 \\
\hline Anti-depressants ${ }^{b}$ & .022 & .005 & -.006 & $.164^{*}$ & .142 \\
\hline Corticosteroids ${ }^{b}$ & -.021 & -.092 & $-.278^{*}$ & -.156 & -.040 \\
\hline Neuroleptics ${ }^{b}$ & .050 & .075 & -.021 & .108 & .120 \\
\hline Tumour load & .150 & .142 & .038 & .088 & -.010 \\
\hline Haemoglobin levels & $.237^{\circ}$ & $.210^{\circ}$ & $.229^{\circ}$ & .121 & $.215^{\circ}$ \\
\hline Creatinine levels & .068 & -.095 & -.103 & -.126 & $-.171^{+*}$ \\
\hline Albumin levels & $.226^{\circ}$ & $.246^{\circ}$ & $.169^{*+*}$ & $.260^{*}$ & $.169^{-*}$ \\
\hline Bilinubin levels & .007 & -.070 & .049 & -.074 & .070 \\
\hline ASAT levels & .047 & -.093 & -.036 & -.046 & -.024 \\
\hline ALAT levels & -.046 & $-.315^{* \prime}$ & $-.167^{-*}$ & -.077 & -.067 \\
\hline LDH levels & .116 & .057 & .046 & .036 & .106 \\
\hline Prior chemotherapy & -.051 & .033 & -.047 & -.083 & -.094 \\
\hline Number of chemotherapy lines & -.083 & .006 & -.126 & -.135 & -.068 \\
\hline Prior immunotherapy & .042 & -.113 & -.125 & $-.208^{\circ}$ & .070 \\
\hline Prior radiotherapy & .074 & $.165^{\circ}$ & .015 & -.015 & .032 \\
\hline Weight loss & .088 & .008 & .126 & $.266^{*}$ & .131 \\
\hline $\begin{array}{l}\text { a The number of opiates given } \\
\text { b Medication was coded given } \\
-p \leqslant .05 \text {. } \\
-p \leqslant .01 \\
-p \leqslant .10 \text {. }\end{array}$ & $\begin{array}{l}\text { ere counted. } \\
\text { or not given(0). }\end{array}$ & & & & \\
\hline
\end{tabular}


Echteld, M.A., Passchier, J., Teunissen, S., Claessen, S., Wit, R. de, Rijt, C.C.D. van der. Multidimensional fatigue and its correlates in hospitalised advanced cancer patients. European Journal of Cancer: 2007, 43(6), 1030-1036

\begin{tabular}{|c|c|c|c|c|c|}
\hline Fatigue dimensions & Independent variables & $\begin{array}{c}\text { Standardized regression } \\
\text { weights }(\beta)\end{array}$ & $\mathrm{t}$ & $p_{\mathrm{t}}$ & $\begin{array}{l}\text { Percentage explained } \\
\text { variance }\left(R^{2}\right)\end{array}$ \\
\hline General fatigue (GF) & $\begin{array}{l}\text { Loss of appetite } \\
\text { Depression } \\
\text { Dyspnoea } \\
\text { Opioid use } \\
\text { Haemoglobin levels } \\
\text { Variables not in the equatior } \\
\text { albumin levels; tumour load }\end{array}$ & $\begin{array}{c}.25 \\
.23 \\
.18 \\
-.22 \\
.18 \\
\text { nausea; anxiety; vomiting; dia }\end{array}$ & $\begin{array}{r}2.71 \\
2.36 \\
2.00 \\
-2.51 \\
1.98 \\
\text { hoea; it }\end{array}$ & $\begin{array}{c}<.01 \\
.02 \\
.05 \\
.01 \\
.05 \\
\text { hiccup }\end{array}$ & .38 \\
\hline Physical fatigue (PF) & $\begin{array}{l}\text { Dyspnoea } \\
\text { Nausea } \\
\text { Anti-convulsant use } \\
\text { ALAT levels } \\
\text { Variables not in the equatior } \\
\text { haemoglobin levels }\end{array}$ & $\begin{array}{c}.30 \\
.20 \\
-.25 \\
-.34 \\
\text { depression; loss of appetite; } h\end{array}$ & $\begin{array}{r}3.27 \\
2.14 \\
-2.74 \\
-3.78 \\
\text { cups; di }\end{array}$ & $\begin{array}{r}<.01 \\
.04 \\
<.01 \\
<.01 \\
\text { coea; a }\end{array}$ & .31 \\
\hline Reduced activity (RA) & $\begin{array}{l}\text { Nausea } \\
\text { Depression } \\
\text { Variables not in the equation } \\
\text { ALAT levels }\end{array}$ & $\begin{array}{c}.49 \\
.26 \\
\text { appetite, diarrhoea; corticoste }\end{array}$ & $\begin{array}{r}3.14 \\
2.60 \\
\text { ids leve }\end{array}$ & $\begin{array}{c}<.01 \\
.01 \\
\text { haemo }\end{array}$ & els; \\
\hline Reduced motivation (RM) & $\begin{array}{l}\text { Depression } \\
\text { Vomiting } \\
\text { Previous immunotherapy } \\
\text { Variables not in the equation }\end{array}$ & $\begin{array}{c}.51 \\
.23 \\
-.26 \\
\text { appetite; anxiety; nausea; dia }\end{array}$ & $\begin{array}{r}6.08 \\
2.76 \\
-3.15 \\
\text { hoea; op }\end{array}$ & $\begin{array}{l}<.01 \\
<.01 \\
<.01 \\
\text { use; }\end{array}$ & 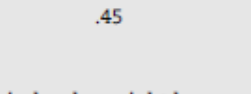 \\
\hline Mental fatigue (MF) & $\begin{array}{l}\text { Anxiety } \\
\text { Pain } \\
\text { Variables not in the equation } \\
\text { creatinine levels }\end{array}$ & $\begin{array}{c}.37 \\
.29 \\
\text { depression; dyspnoea; appetit }\end{array}$ & $\begin{array}{c}3.94 \\
3.11 \\
\text { nausea; }\end{array}$ & $\begin{array}{l}<.01 \\
<.01 \\
\text { miting }\end{array}$ & grountevers, \\
\hline $\begin{array}{l}\text { Standardised regression w } \\
\text { values associated with the } \\
\text { of common variance betv } \\
\text { dimension. " } p<.01 \text {. } \\
\text { a Variable entered into th }\end{array}$ & $\begin{array}{l}\text { ts (indicating the strength } \\
\text { ression weights, their signi } \\
\text { all independent variables } \\
\text { ression equation, but not }\end{array}$ & $\begin{array}{l}\text { association between the ir } \\
\text { ce levels ( } p \text {-values), and perc } \\
\text { he regression equation and } \\
\text { ted (probability of } F \leqslant .10 \text { ). }\end{array}$ & $\begin{array}{l}\text { ende } \\
\text { ages e } \\
\text { outcc }\end{array}$ & $\begin{array}{l}\text { iables } \\
\text { ied va } \\
\text { aniabl }\end{array}$ & $\begin{array}{l}\text { the outcome variable), } t \text { - } \\
\text { (indicating the amount } \\
\text { shown for each fatigue }\end{array}$ \\
\hline
\end{tabular}

